\title{
OVARIAN OESTROGEN LEVELS IN THE NON- PREGNANT MARE: \\ RELATIONSHIP TO HISTOLOGICAL APPEARANCE OF THE UTERUS AND TO CLINICAL STATUS
}

\section{ODD KNUDSEN AND WEIERT VELLE}

\author{
Department of Obstetrics, Royal Veterinary College, Stockholm, Sweden, and \\ Department of Reproductive Physiology and Pathology, Veterinary College of Norway, \\ Oslo, Norway
}

(Received 30th September 1960)

Summary. The oestrogen levels in follicular contents have been estimated for thirty-two non-pregnant mares in different phases of the oestrous cycle, and for three sterile mares with ovarian dysfunction. The estimations were made by use of a highly specific chemical method, which permitted the separate determination of oestrone and oestradiol$17 \beta$. The phases of the oestrous cycle for each mare were determined by clinical observations, post-mortem examinations of the genital organs and histological investigations of the uterus. In pro-oestrus, circumscribed groups of glandular ducts which are typical for this phase, but which do not seem to have been reported previously, have now been described. In the oestrous group of mares, the levels of both oestrone and oestradiol- $17 \beta$ found were highly significantly elevated when compared with the values for the mares in the other phases of the cycle taken together $(P<0.0005)$. In the anoestrous group, a significantly elevated level of oestradiol-17 $\beta$ was recorded for animals with autumn follicles, when compared with the other mares in this group $(P<0 \cdot 05)$. Two mares which had persistent follicles and were placed in the metoestrous group showed elevated oestrogen values. In two cases diagnosed as cystic glandular endometritis, high oestrogen levels were encountered. In a single mare with a follicle present for a continuous period of at least 3 months (probably for more than 1 year), no oestrogens were demonstrated in the follicular fluid in spite of clinical signs of heat. In all mares except the last, oestradiol-17 $\beta$ was present in large amounts, relatively to oestrone. The mean values for the total amount of follicular contents analysed were $33.8 \mu \mathrm{g}$ oestradiol- $17 \beta$ and $2.3 \mu \mathrm{g}$ oestrone per $100 \mathrm{ml}$ (uncorrected values).

\section{INTRODUCTION}

Most theories concerning the endogenous hormonal factors responsible for the different functional states of the endometrium of domestic animals are based 
on more or less indirect evidence. Hormone determinations performed in combination with histological examinations are few. This, of course, has mainly been due to the lack of reliable analytical methods. For determination of oestrogenic hormones, chemical methods of high specificity and sensitivity are now available.

In the pregnant mare, the urinary oestrogens have been extensively studied. Very few investigations, however, have been made in the non-pregnant animal and the applicability of chemical methods to the presumably low levels of urinary oestrogens in the non-pregnant mare remains to be elucidated. But even if applicable, hormone determinations on 24-hr collections of urine, which may be considered the most reliable measure of hormone production, is only seldom practicable in large domestic animals.

Instead, it was found of interest to investigate ovarian oestrogen levels in mares in different reproductive states. In the course of this work, which was carried out during the years 1958-60, oestradiol-17 $\beta$ was identified as the quantitatively most important oestrogen of mare follicular fluid. Oestrone was also demonstrated, but in trace amounts only. These findings are contradictory to the results reported by Andrews \& McKenzie (1941), but agree well with the findings reported by Short (1960).

In addition to oestradiol- $17 \beta$ and oestrone, a third oestrogen, 6-hydroxyoestradiol-17 $\beta$, has recently been isolated from mare follicular fluid (Bush, Klyne \& Short, 1960).

The purpose of the present investigation has been to correlate ovarian oestrogen levels with the different phases of the oestrous cycle. Some observations on pathological ovaries are also included.

\section{MATERIAL AND METHODS}

The material included thirty-two mares, twenty-six of heavy breeds (Belgians and North Swedish), four of American Standard breeds, and two halfbreeds; the ages ranged between 12 and 20 years (Text-fig. 1). In addition, observations for three mares showing abnormal ovarian function are given. The reason for the slaughter of five mares was sterility. Of these, three had ovarian dysfunction, and two had partial uterine dilatation (Knudsen, 1961). The remaining thirty horses were slaughtered for lameness or for other irrelevant reasons.

Follicular contents were collected by puncture with a Day's cannula (four animals), after ovariectomy (one animal) or within 10 min after slaughter.

When a single large follicle was present, material was collected from that one only. In other ovaries, several small follicles were punctured, but contents were in these cases collected only from follicles protruding above the surface of the ovary. No attempt was made to determine the total volume of follicular contents of the ovaries and the oestrogen levels are given per unit volume. In order to stop all enzyme activity, the contents after collection were immediately transferred to a bottle containing $5.0 \mathrm{ml}$ concentrated hydrochloric acid.

At the time of collection of follicular contents, the phase of the oestrous cycle of the mare was determined. As far as possible, visible signs of heat were recorded. In most cases, it was, however, not possible to use stallions for teasing. 
Vaginal inspection and rectal palpation were carried out. The cytological status of the uterine mucosa was determined by examination of orcein-stained smears taken with a uterus sample collector (Knudsen, 1959).

The ovarian status was analysed on post-mortem material according to the method of Arthur (1958). Tissue specimens from corpus and cornuae uteri were fixed in Bouin's solution and stained with eosin and haematoxylin and with van Gieson's stain. The different oestrous phases were histologically evaluated, mainly according to the methods of Andrews \& McKenzie (1941) and Ressang (1954).

Oestrogen determinations were performed in the manner described by Brown (1955). The samples of follicular contents were usually kept for some time at $-25^{\circ} \mathrm{C}$. Immediately following thawing, the samples were diluted with distilled water to a final volume of $100 \mathrm{ml}$, and extracted with $3 \times 100 \mathrm{ml}$ ethyl ether. The emulsions formed were broken by short-time centrifugation. The combined extracts were washed and processed by Brown's method, except that $\mathrm{n}$-Hexane was used instead of petroleum ether for chromatography (Diczfalusy \& Lindqvist, 1956). No attempt was thus made to differentiate between 'free' and 'bound' oestrogens. Woelm alumina (neutral) was found very satisfactory for chromatography when deactivated by the addition of $10 \%$ water $(\mathrm{w} / \mathrm{w})$. Otherwise, the same grades of reagents were used as in previous investigations (Velle, 1958). Losses of oestrogens during methylation and chromatography amounted to about $20 \%$. All reported values are uncorrected.

The results of the hormone determinations were treated statistically by the analysis of variance.

\section{RESULTS}

\section{Anoestrus}

None of the eight mares in this group had been in heat during the last month before collection of the follicular contents. In four of the animals, one of the ovaries contained one large follicle of the type described clinically by Burkhardt (1948). The contents of these autumn follicles were bloody and of a liquid to gelatinous consistency (Pl. 1, Fig. 1). The surface and glandular epithelia of the uterus were cuboidal. The glandular lumina were narrow and empty. The mean oestrogen levels recorded for the anoestrous mares were $7.5 \mu \mathrm{g}$ oestradiol- $17 \beta$ and $0.5 \mu \mathrm{g}$ oestrone per $100 \mathrm{ml}$. The mean oestrogen levels of the autumn-follicle mares were $11.3 \mathrm{\mu g}$ oestradiol- $17 \beta$ and $0.4 \mathrm{\mu g}$ oestrone per $100 \mathrm{ml}$, compared with 3.7 and $0.6 \mu \mathrm{g}$, respectively, for the other four animals in this group. This difference in oestradiol concentration was significant $(P<0 \cdot 05)$. The oestrone levels were extremely low, probably at the sensitivity limit of the method, and no significant difference was found between the groups.

\section{Pro-oestrus}

Five mares in this group had not yet shown signs of heat in the current breeding season. The remaining three had been in heat earlier in the same season. All mares had ovaries with growing follicles. The histological appearance 
PIAIE:

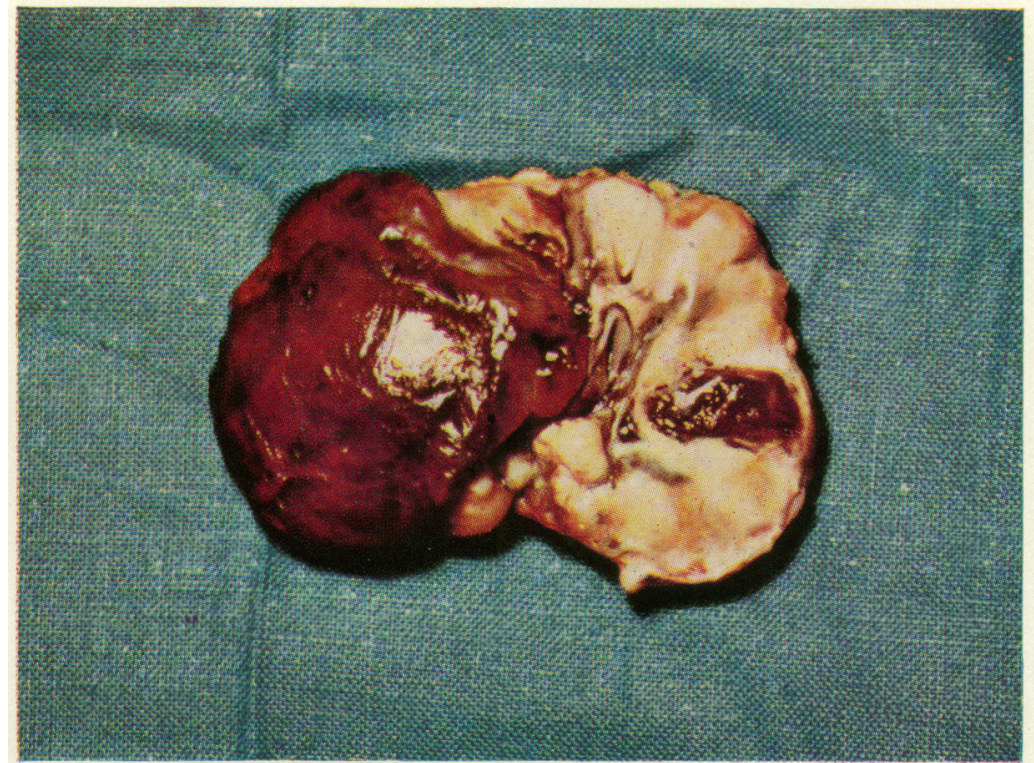

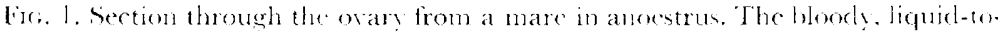
ecelations formation protruding from the ovarian surface represents the contents of what is designated an autum follete colinically a form of persistent follicles. 
PLA'E' 2

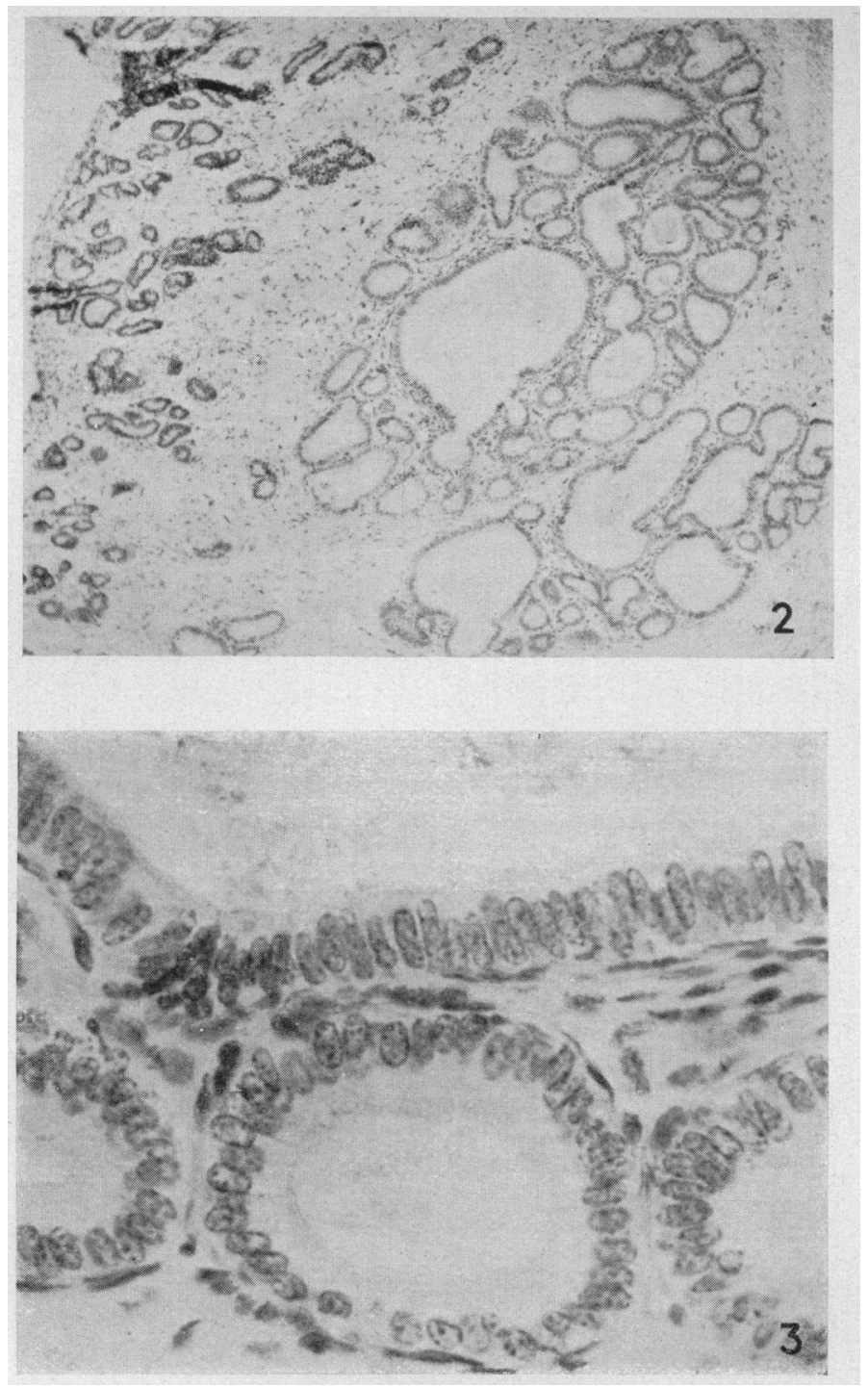

Fig, 2. Section of endometrium demonstrating the characteristic groups of glandular lumina appearing during pro-oestrus. (Approx. $60 \times$ ). FIG. 3. Higher magnification of glandular structures corresponding to those seen in Fig. 2. (Approx. 600x).

(Facing p. 133) 
of the uterine glands in this phase was distinctly different from the picture seen in the other phases. The surface epithelium, like the epithelium of most of the uterine glands, was cuboidal and relatively rich in chromatin. Most of the glandular lumina were rather narrow. In sections, numerous circumscribed groups of glandular lumina appeared in the stroma (Pl. 2, Figs. 2 and 3). The groups had marked boundaries. The epithelium in these groups was high, cylindrical, with markedly paler nuclei than in the surrounding epithelium. The glands were often highly dilated, and often contained homogeneous eosinophilic material. The mean oestrogen levels recorded for the follicular contents for the mares in this group were $7.1 \mu \mathrm{g}$ oestradiol-17 $\beta$ and $0.9 \mu \mathrm{g}$ oestrone per $100 \mathrm{ml}$ (Text-fig. 1).

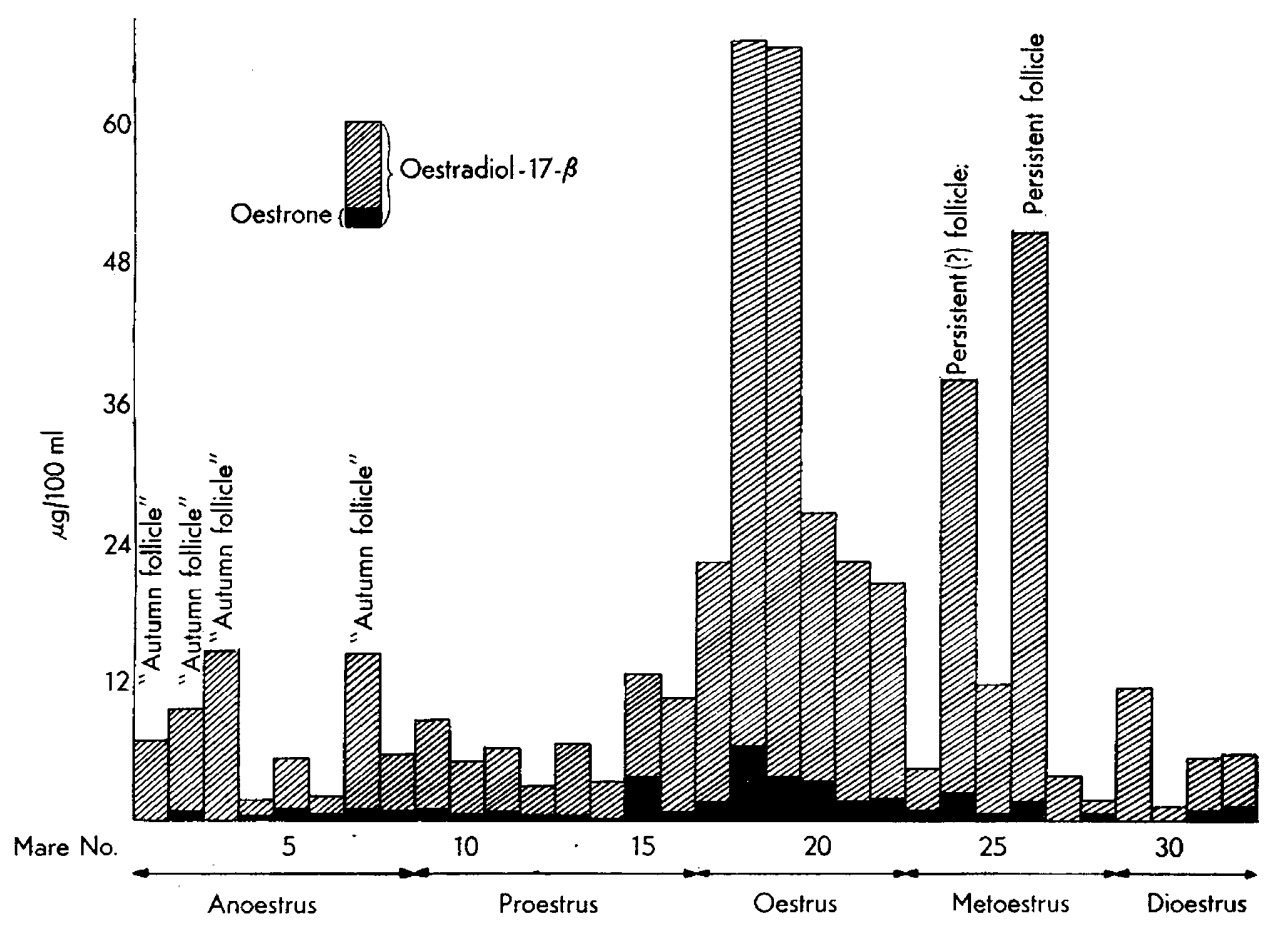

TEXT-FIG. 1. The results of oestrogen determinations in follicular contents from mares in different phases of the oestrous cycle.

\section{Oestrus}

These mares showed signs of heat and their ovaries contained one or two large follicles. The uterine stroma was more or less oedematous, the surface and glandular epithelia were high and glassy, with swollen, pale nuclei. The stroma contained many evenly distributed, wide glandular lumina of about equal diameter. The average oestrogen levels found for the oestrous group of mares were $37.5 \mu \mathrm{g}$ oestradiol- $17 \beta$ and $3.0 \mu \mathrm{g}$ oestrone per $100 \mathrm{ml}$ follicular fluid. Both values were significantly higher in this phase than the values for the two hormones in the rest of the series taken together, represented in Text-fig. I (9.6 and 0.7 $\mathrm{\mu g}$, respectively; $P<0.0005$ for both hormones). 


\section{Metoestrus}

None of these mares were in heat. In most of the animals, it was not possible to obtain information on which day the oestrus signs subsided. In one mare (No. 26), one ovary contained a persistent follicle which was checked by palpation daily during and after heat to the time of ovariectomy. The term 'persistent follicle' thus implies a follicle which from the clinical examination cannot be said to have ruptured. Mare No. 24 was not examined till slaughter. But from the consistency and the post-mortem appearance of the follicle, it seems that this follicle should also be classified as persistent. Both these follicles had the same consistency and incision surface as autumn follicles (see Pl. 1, Fig. 1). In sections the glandular epithelium dominated the endometrium, and the glandular lumina were wide. The histological appearance of the endometrium was, moreover, characterized by high surface and glandular epithelia, and above all by a high mitotic activity. As shown in Text-fig. 1, the oestrogen levels of the follicles diagnosed as persisting were very high compared with the other values in this group.

\section{Dioestrus}

The four mares in this group had shown signs of heat in the breeding season. No growing follicles were observed. The surface and glandular epithelia were cuboidal, and the glandular lumina narrow. The oestrogen levels were low, with individual averages of $6.0 \mu \mathrm{g}$ oestradiol- $17 \beta$ and $0.5 \mu \mathrm{g}$ oestrone per $100 \mathrm{ml}$.

\section{Cystic glandular endometritis (?)}

Case 1. An 18-year-old mare (American Standard breed), which had been barren for the last 4 years. The mare was continuously receptive to the stallion throughout the year. As judged by vaginal inspection, the mare had abnormally long oestrous periods throughout the year. For some days following heat, substantial amounts of gelatinous white mucus were discharged. The ovaries constantly contained large follicles, most of which regressed. The uterus was big, but the consistency did not depart from that of a normal mare. The mare was slaughtered in November. The ovaries then contained several large follicles, of which three showed the same picture as autumn follicles. The surface and glandular epithelia were cuboidal. Many of the glandular ducts were dilated with protein-like precipitations in the lumen, and lined by low, flat epithelium. The stroma contained moderate numbers of leucocytes and plasma cells. The oestrogen levels in the follicular fluid at slaughter were high: $73 \mu \mathrm{g}$ oestradiol- $17 \beta$ and $1.7 \mu \mathrm{g}$ oestrone per $100 \mathrm{ml}$.

Case 2. A 23-year-old mare (Belgian), which had been barren at the age of 21 and was not mated later. As far as the present owner knew, the mare had been pregnant twice after the age of 15, but had aborted both times. At slaughter, the mare was in heat. In the left ovary, several follicles with bloody, gelatinous contents were present. The largest follicle had a diameter of $4 \mathrm{~cm}$. The right ovary contained a follicle of $5 \mathrm{~cm}$ diameter with a thick wall in which numerous congested blood vessels were observed. With the exception of a moderate occurrence of dilated glandular ducts with a low epithelium, the 
histological appearance of the uterus corresponded to that of a normal mare in heat. The oestrogen levels found were $191 \mu \mathrm{g}$ oestradiol-17 $\beta$ and 13.1 $\mu \mathrm{g}$ oestrone per $100 \mathrm{ml}$ follicular contents.

\section{A case with a permanent follicle}

This was a 10-year-old mare (American Standard breed), which had had several foals but had been barren for the last 2 years. She had more extended periods of heat, and more pronounced signs of heat, than normal. During the first year, the mare was examined three times, and on each occasion a thinwalled follicle of 5 to $7 \mathrm{~cm}$ diameter was found in the left ovary. Its nature was distinctly different from that of a parovarian cyst. The next year, a similar follicle was observed in the same ovary; the mare was examined every second or third day for a longer period. In this way, it was established that the follicle did not rupture, but its size varied from 4 to $7 \mathrm{~cm}$ in diameter. After the mare had been treated alternately with oestrogens and gonadotrophins over four or five heat periods, the follicle was punctured with a Day's cannula in a period of heat. In spite of several matings, the mare remained barren that season, and was afterwards put in training. The oestrogen levels of the fluid obtained by puncture were zero for both oestradiol-17 $\beta$ and oestrone.

\section{DISGUSSION}

Andrews \& McKenzie (1941) maintained that only negligible amounts of follicular fluid were lost when the follicles were punctured in vivo. In our experience, considerable losses of fluid often take place in connection with puncture, and since collection of the entire amount of follicular fluid from an ovary is obviously impossible to carry out with even a low degree of precision, we felt that determinations of follicular volumes would be of minor interest, especially since our material includes follicles punctured in vivo as well as after slaughter. It must be assumed, however, that of all the elements of the ovary, the follicular contents possess the highest levels of oestrogens. Samples of such material were therefore assumed to be representative for the ovarian activity with respect to oestrogens. By expressing the hormone concentrations per unit volume, comparisons should then be possible regardless of actual amounts of follicular fluid present, provided that enough material is collected for analysis.

In material from mares chosen at random, it is in practice very difficult to determine exactly the phase of the cycle. In our material, this is especially true for the mares for which the owners did not accurately record the beginning and cessation of heat. The classification of the animals in the different phases of the cycle has, therefore, mainly been based on histological examinations of the endometrium, with additional support from the post-mortem examination of uterus and ovaries. Only in those instances in which we ourselves had the opportunity of ascertaining the external signs of heat could the latter observations be fully trusted.

The histological appearance of the uterus in the different phases of the cycle conforms generally to the descriptions given by Andrews \& McKenzie (1941) and Ressang (1954). One deviation has, however, been noted for pro-oestrus. 
In this phase, all mares showed abundant occurrence of circumscribed groups of glands of the type shown in Pl. 2, Figs. 2 and 3. The morphology of the glandular epithelium in these groups, and the often wide lumina, indicate obturation of the excretory ducts. This picture may be interpreted as newly awakened activity of secretory elements. As this picture is so pronounced that it would be difficult to overlook, it seems most peculiar that it has not earlier been taken as characteristic for pro-oestrus. But the possibility exists that the described picture may be more pronounced in our material than it would be if, in addition, other breeds and animals of other geographical origins were represented.

As regards the oestrogen levels, a fairly good correspondence exists between the values recorded in this investigation and the results given by Short (1960) for both oestradiol-17 $\beta$ and oestrone, in spite of the different methods of extraction and separation. In the present investigation, a total of $766.5 \mathrm{ml}$ of follicular contents was analysed. Total oestrogens recorded were $33.8 \mu \mathrm{g}$ of oestradiol- $17 \beta$ and $2.3 \mu \mathrm{g}$ of oestrone per $100 \mathrm{ml}$. Our figures are uncorrected and must be taken to represent, at most, $80 \%$ of the true values. Short's figures, based on analysis of a single batch of $500 \mathrm{ml}$ of follicular fluid, were 46 and $3.4 \mathrm{ug}$ per $100 \mathrm{ml}$, respectively.

These oestrogen levels in mare follicular fluid were indicated already in 1939, when Dingemanse \& Mühlbock, using bioassay and analysing large batches of fluid, found levels of 3500 to $4200 \mathrm{i} . \mathrm{u}$. $/ 100 \mathrm{ml}$. Regarding the fact that oestradiol-17 $\beta$ represents most of the oestrogens present, as shown by Short (1960) and in the present paper, the figures of Dingemanse \& Mühlbock would correspond to a level of the order of $40 \mu \mathrm{g}$ oestradiol- $17 \beta$ per $100 \mathrm{ml}$ fluid. The good agreement in these three investigations is contradictory to the approximately ten times higher values obtained by use of a photometric method by Mayer, Andrews \& McKenzie (1940).

From our observations, pronounced differences in oestrogen levels in different mares and groups of mares are obvious. This is also in contrast to the findings reported by Mayer et al. (1940) and by Andrews \& McKenzie (1941), who state that the oestrogen concentration, when calculated per unit volume, seems to be almost constant.

The variations observed in the present investigation require interpretation. Quite generally, it is dangerous to take actual concentrations of hormones in a gland as a measure of the hormone production of this gland, especially as long as the rates of disappearance of the secretory products are unknown. When, however, the effect of oestrogenic hormones on the uterine histological picture, well known from experimental work, is considered in connection with the present observations, it seems reasonable to assume that the elevated oestrogen levels in the oestrous-group mares really represent increased production. The same consideration would certainly also apply to the two reported cases diagnosed as cystic glandular endometritis. Interpretative difficulties arise for the two cases of persistent follicles (mares No. 24 and 26). In these two mares, no external signs of heat were observed at the time of sample collection. Nevertheless, the ovarian oestrogen levels were high in both cases. No obvious explanation of this finding is evident. The possibility of decreased disappearance 
rates for the hormones might be mentioned. The same might apply to the four animals with autumn follicles, in which oestradiol levels were significantly higher than for the four other mares in this group. The peculiar nature of the follicular contents in these cases might possibly have a bearing on this problem. However, other hormonal factors in addition to oestrogens must be responsible for the clinical signs of heat. This has been clearly shown for the cow by one of the authors. A non-pregnant cow with normal cycles and marked psychic signs of heat was given a single intramuscular injection of a suspension of $75 \mathrm{mg}$ crystalline oestrone on Day 3 following heat. Because of the depot effect of this preparation, the urinary oestrogen levels, as determined chemically on successive 24-hr samples, were highly elevated for more than one month. Despite this, no psychic signs of heat were observed following the injection, until 21 days following the last heat (18 days after the injection) when strong signs again appeared (Velle, unpublished observation).

It is possible, therefore, that other hormonal factors must also be taken into consideration when an explanation is sought for the observations made on these mares.

The mare with a permanent follicle is interesting from a diagnostic point of view. It shows that an apparently mature follicle present in the ovary of a sterile mare in heat may not be responsible at all for the clinical signs of heat.

The material represented in Text-fig. 1 contains two abnormal mares with uterine dilatation. This local process does not, however, influence ovarian function (Knudsen, 1961). On the other hand, it is not possible to decide the effect that the high median age of the mares in our material may have on the results obtained.

\section{ACKNOWLEDGMENTS}

This investigation has been supported financially by Exportmedelsfonden, Stockholm, Sweden, and by the Agricultural Research Council of Norway.

\section{REFERENCES}

Andrews, F. N. \& McKenziE, F. F. (1941) Estrus, ovulation and related phenomena in the mare. Bull. Mo. agric. Exp. Sta. No. 329.

ARTHUR, G. H. (1958) An analysis of the reproductive function of mares based on post-mortem examination. Vet. Rec. 23, 682.

Brown, J. B. (1955) A chemical method for the determination of oestriol, oestrone and oestradiol in human urine. Biochem. F. 60, 185.

Burkhardt, J. (1948) Some clinical problems of horse breeding. Vet. Rec. 60, 243.

Bush, I. E., KLYNE, W. \& ShORT, R. V. (1960) The isolation of 6-hydroxy-oestradiol-17 $\beta$ from follicular fluid of the mare. F. Endocrin. 20, i.

Diczfalusy, E. \& Lindevist, P. (1956) Isolation and estimation of 'free' oestrogens in human placenta. Acta endocr., Copenhagen, 22, 203.

Dingemanse, E. \& Mühlbock, O. (1939) Über die freien und gebundenen oestrogenen Hormone im Ovarium des Pferdes, der Kuh und des Schweines. Acta brev. neerl. Physiol. 9, 95.

Knudsen, O. (1959) En uterusprovtagare och dess användning. Medlemsbl. Sverig. Veterinärförbund, 11, 239.

KNUDSEN, O. (1961) Dilatation of uterus in the mare (in press).

Mayer, D. T., Andrews, F. N. \& McKenzie, F. F. (1940) The estrin content of the follicular fluid and urine of the mare and its relation to phenomena of the estrual cycle. Endocrinology, 27, 867.

Ressang, A. (1954) Steriliteit bij de merrie. Thesis, Drukkeij G. van Dijk, Breukelen.

SHort, R. V. (1960) Steroids present in the follicular fluid of the mare. F. Endocrin. 20, 147.

VELLE, W. (1958) Undersökelser over naturlig forekommende östragener hos drövtyggere og gris. Thesis, Oslo. 